\title{
NurseCare: Design and 'In-The-Wild' Evaluation of a Mobile System to Promote the Ergonomic Transfer of Patients
}

\author{
Maximilian Dürr, Carla Gröschel, Ulrike Pfeil, Harald Reiterer* \\ HCI Group, University of Konstanz \\ \{maximilian.duerr, carla.groeschel, ulrike.pfeil, harald.reiterer\}@ uni.kn
}
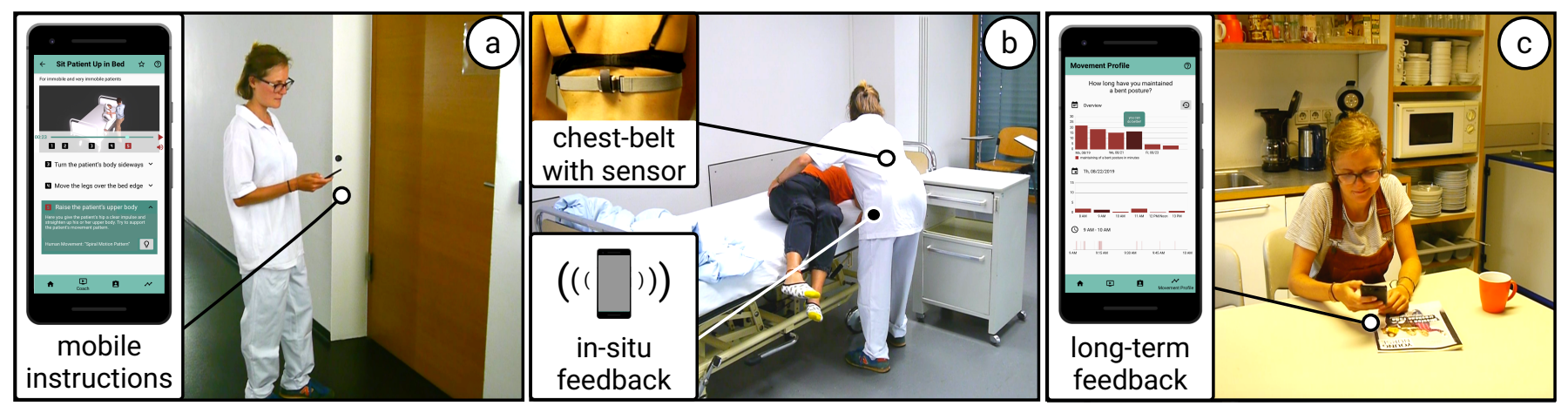

Figure 1. The key features of NurseCare: (a) Mobile access to instructions for ergonomic patient transfers (e.g., to access instructions before entering a patient's room). (b) In-situ feedback related to the risky bending of the back. A sensor attached to a chest-belt detects the risky bending of a user's back. The smartphone vibrates to provide in-situ feedback. (c) Long-term feedback to aid reflection (e.g., for reflection during breaks or at home). (Material design icons in (a) and in (c), OGoogle LLC; Humans in (a), OReallusion Inc.; Hospital furniture in (a), (T) TurboSquid Inc.)

\section{ABSTRACT}

Nurses are frequently required to transfer patients as part of their daily duties. However, the manual transfer of patients is a major risk factor for injuries to the back. Although the Kinaesthetics Care Conception can help to address this issue, existing support for the integration of the concept into nursingcare practice is low. We present NurseCare, a mobile system that aims to promote the practical application of ergonomic patient transfers based on the Kinaesthetics Care Conception. NurseCare consists of a wearable and a smartphone app. Key features of NurseCare include mobile accessible instructions for ergonomic patient transfers, in-situ feedback for the risky bending of the back, and long-term feedback. We evaluated Nurse Care in a nine participant 'in-the-wild' evaluation. Results indicate that NurseCare can facilitate ergonomic work while providing a high user experience adequate to the nurses' work domain, and reveal how NurseCare can be incorporated in given practices.

*The first two authors contributed equally to this research.

Permission to make digital or hard copies of part or all of this work for personal or classroom use is granted without fee provided that copies are not made or distributed for profit or commercial advantage and that copies bear this notice and the full citation on the first page. Copyrights for third-party components of this work must be honored. For all other uses, contact the owner/author(s).

CHI '20, April 25-30, 2020, Honolulu, HI, USA.

(C) 2020 Copyright is held by the author/owner(s).

ACM ISBN 978-1-4503-6708-0/20/04.

http://dx.doi.org/10.1145/3313831.3376851

\section{Author Keywords}

mobile system, 'in-the-wild' evaluation, nursing care

\section{CCS Concepts}

-Human-centered computing $\rightarrow$ Human computer interaction (HCI);

\section{INTRODUCTION}

The demographic developments in western societies entail an increasing need for nursing-care personnel who can care for a growing portion of elderly society members. However, especially nursing-care workers are highly affected by injuries from overexertion [24] and work-related musculoskeletal disorders [34]. Related injuries include problems of the back, neck, and shoulder. Such health implications can lead to sick leave [9] and persistent medical problems [22]. One major risk factor for related symptoms is the manual transfer and movement of patients $[32,10]$.

To reduce negative health implications, multiple governmentsupported schools in Germany provide a Kinaesthetics Basics Course that teaches nursing-care students about the transfer of patients based on the Kinaesthetics Care Conception [1] (henceforth referred to as Kinaesthetics). Kinaesthetics consists of six concepts that can help to view human activities from different perspectives [15]. For example, the concept 'human movement' can help nurses to reduce the load on their bodies during certain parts of a patient transfer by following spiral instead of parallel movements. Kinaesthetics is supposed to enable the transfer of patients so that the health 
development of nurses and patients is supported while injuries are avoided. However, previous studies have shown that the internalization and application of Kinaesthetics often fail [11,8]. Problems stated are a lack of sufficient knowledge regarding the appliance and direct support during work. After the Kinaesthetics Basic Course, nurses are hardly provided with any support to apply Kinaesthetics as part of their daily work [8].

We present NurseCare, a mobile system that aims to promote the practical application of ergonomic patient transfers based on Kinaesthetics during work. NurseCare is comprised of two components: a wearable and a smartphone app. The key features of NurseCare include mobile access to instructions for ergonomic patient transfers (see Figure 1a), in-situ feedback related to the risky bending of the back (see Figure 1b), and long-term feedback to aid reflection (see Figure 1c).

To our knowledge, NurseCare is the first mobile system that provides instructions and feedback in order to promote the application of ergonomic patient transfers during work. In contrast to previous studies, our work contributes by an 'inthe-wild' evaluation in a clinical setting, which investigates how nurses experience the support of NurseCare during work.

In the following, we give an overview on related research, describe our user-centered design process and the features of NurseCare, present and discuss the findings of our 'in-thewild' evaluation, and provide implications for the design and integration of related mobile systems and future work.

\section{RELATED WORK}

In order to promote the ergonomic transfer of patients, it is important to (i) make users aware of risky postures, and to (ii) support the correct application of ergonomic patient transfers. We consequently reviewed related work in both directions.

\section{Mobile Systems to make aware of Risky Postures}

Previous research investigated several mobile systems that use wearable technology to detect risky postures and provide feedback in real-time. Yan et al. [37] target construction workers. They make use of wearable inertial measurement units for tracking and warn users through a smartphone if a risky posture is detected. The authors validated their system in the form of a lab-experiment with one participant and provide a very brief description of a subsequent field study. Soenandi et al. [33] concentrate on the specific use case of workers in the cottage industry of Emping melinjo, an agro-industrial product. Du et al. [7] investigated a mobile system that supports office workers in maintaining a healthy posture. The authors combine the smart-garment Zishi [36] with a smartphone app to track users' shoulder posture and to support shoulder training. They evaluated the usability of the shoulder training in a lab study, and investigated the effectiveness of the shoulder tracking as part of a field experiment. Their results indicate a positive usability for the shoulder training, and that the shoulder tracking can help to improve participants' posture.

Without a focus on a specific task, other prior work concentrated on posture correction in general. For instance, Carvalho et al. [6] evaluated a vest that provides audio and tactile feedback for incorrect postures. The authors' results indicate that the system can decrease the percentage of time which users spend in an incorrect posture. In relation, the approach of Shanmugam et al. [29] uses a wearable to track the lumbar spine position. When a bad posture is detected, the system provides users with tactile feedback and a push-notification on a smartphone app. Furthermore, there also exist some commercial products that combine a wearable with a smartphone app to provide users with feedback for risky postures (e.g., [35]).

In the field of health care, various systems target at-home monitoring (e.g., [30]). Related to ergonomic patient transfers, Muckell et al. [23] investigated different risk metrics for patient transfers. Based on their results of a lab study, they suggest that wearable tracking technology allows for the detection of risky patient transfer behavior.

Overall, past work shows that mobile systems can be effective in decreasing risky postures. However, much past research focused on studying the effectiveness of tracking approaches in a lab. To our knowledge, past work did not investigate how nurses experience a mobile system that aims to increase their awareness of risky postures in a clinical setting during work.

Mobile Systems to support Ergonomic Patient Transfers Past research related to nursing care considered mobile systems for the learning of different core skills, including the communication with patients [3] and emergency handling [14].

Concerning patient transfers, some past work researched stationary learning systems. For instance, Huang et al. [16] presented a system that provides videos and visual feedback to support the training of patient-transfer skills. Based on an evaluation, the authors suggest that participants who used their system showed a higher performance improvement for patient transfers than participants who learned with a textbook and demonstration video.

There is only few previous research that used mobile technology to promote ergonomic patient transfers. Kopetz et al. [21] investigated the use of smart glasses to support nurses' skills training. They designed and evaluated an app that supports instructions for a patient transfer scenario. Their results suggest that smart glasses have the potential to support skills training, but also that most participants could not imagine using the technology as part of their daily work. Dürr et al. [8] propose a concept for a system that uses tablets to support the learning of patient transfers. Furthermore, there exist two commercial apps related to Kinaesthetics [20]. The tablet app 'Kinaesthetics Care' aims to support the training of patient transfers with videos and textual information. 'MH Kinaesthetics' is a smartphone app that is limited to textual descriptions and images for different aspects of Kinaesthetics.

Overall, the reviewed research provides no empirical evidence to what extent a mobile system can support the application of ergonomic patient transfers during work. To our knowledge, past research did not leverage mobile technology to support the ergonomic transfer of patients directly during work.

NURSECARE: A MOBILE SYSTEM TO SUPPORT NURSES In the following, we describe the design and implementation of NurseCare, a mobile system to promote the ergonomic 
transfer of patients based on Kinaesthetics. Our user-centered design process was conducted in German. Thus, the photos of the design artifacts in this section contain German writing. Our design process was based on the results of a previously conducted qualitative study [8]. The results of this study provide a broad understanding of the targeted context with a focus on the learning process as part of nursing-care students' education. Our design process extended this broad understanding of the context with specifics about support during work. For this purpose, we conducted two workshops, which were largely inspired by participatory design (e.g., [18]) and participatory research 'in-the-wild' [26]. Both workshops were conducted together with nursing-care students who had practical work experience in a clinical context.

\section{Workshop I: Requirements and Initial Design Ideas}

To gather requirements and first design ideas for NurseCare, we conducted a 2.5 hours long workshop with five nursing-care students (all female). The participants were aged between 22 and 50 years. All had previously participated a Kinaesthetics Basic Course. Participants were compensated with 25 Euro. The workshop structure was inspired by the three phases of the Future Workshop [19]: (i) Critique Phase, (ii) Fantasy Phase, and (iii) Implementation Phase.

In the Critique Phase, we conducted a structured brainstorming (see Figure 2a). We aimed to reveal issues regarding the appliance of Kinaesthetics as part of nurses' daily work and to gather ideas for solutions to existing problems.

In the Fantasy Phase, the participants were divided into two groups. They were asked to choose the three of the solution ideas that came up during the brainstorming, which they deemed the most important ones. For each idea, they were asked to sketch out first ideas for its realization (see Figure 2b).

The Implementation Phase comprised the presentation and discussion of the groups' works. Based on the workshop results, we identified important requirements. Figure $2 \mathrm{c}$ shows the five main requirements that informed the design and implementation of NurseCare.

\section{Workshop II: Designing for the Nurses Daily Workflow}

The first workshop highlighted different problems related to the nurses' workflow. We conducted a second 2.5 hours long workshop in order to discern how a mobile system may address the identified requirements in a way that supports the nurses' complex workflow. As the aim of this workshop was the combination of domain-relevant knowledge and technical knowledge, we incorporated the expertise of nurses and computer-science students. Six persons (5 female) participated. Three nursing-care students who took part in workshop I, and three computer-science students with a background in HCI. The participants were aged between 22 and 28 years. Participants were compensated with 25 Euro.

We applied the framework of Sanders et al. [27] to chose appropriate tools and techniques for the workshop. The participants were grouped in dyads, each comprised of one nursing-care and one computer-science student. Each dyad received a large piece of paper, with an orange, a yellow, and a blue line (see

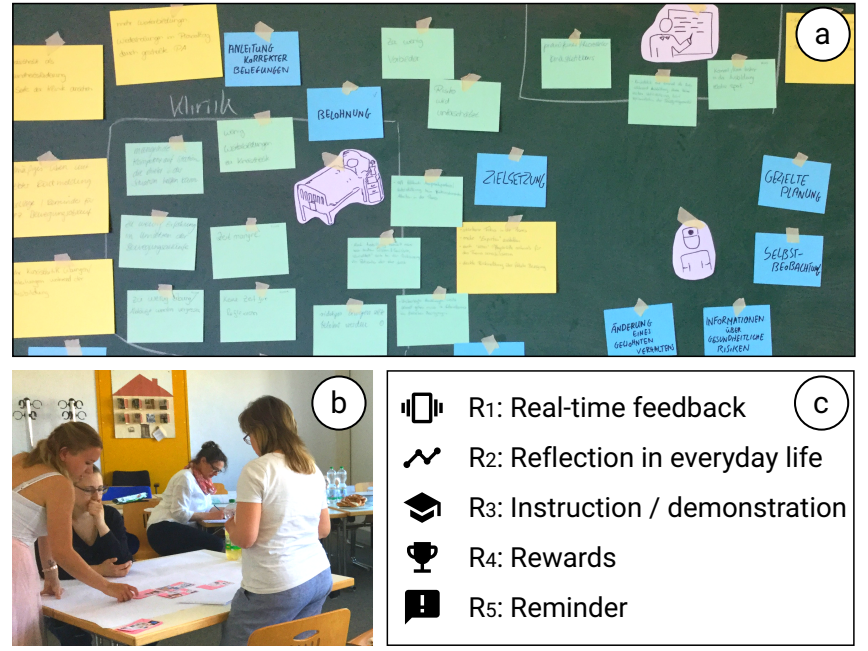

Figure 2. Workshop I: Requirements and Initial Design Ideas. (a) results of the brainstorming in the Critique Phase, (b) sketching ideas in the Fantasy Phase, (c) the five main requirements, based on the workshop results. (Material design icons in (c), OGoogle LLC)
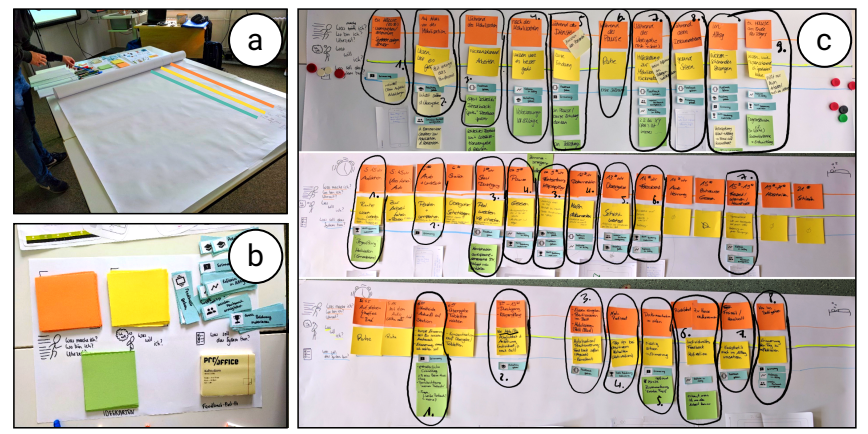

Figure 3. Workshop II: Designing for the Nurses Daily Workflow. (a) timeline template provided to the participants (colored lines were enhanced with a graphics tool, to increase the perceptibility of the image), (b) colored paper cards to reflect different information about events in the nurses' daily workflow, (c) analysis by grouping of similarities.

Figure 3a). The three lines were supposed to reflect different information on the same timeline. The dyads were asked to fill the timeline with information about a regular workday, and extend this towards a 'dream scenario' in which they are supported by a mobile system. They were told that they should start when they get up and end the scenario when going to bed. To do so, the dyads were provided with colored paper cards, which they could stick to the matching lines on the timeline (see Figure 3b). For each event during a regular workday, the participants were asked to provide information about what they usually do at the time (orange cards), what they want to achieve by what they do (yellow cards), and match one or multiple of the previously identified requirements to the task if suitable (blue cards). Furthermore, participants were asked to use green cards to provide ideas about how a future system may aid them related to the requirements. In a second step, the participants were asked to sketch out how they imagine the previously noted ideas to be realized in a future system.

The results were analyzed in two steps. At first, each group's artifact was described individually in a written form. Second, 
photos of all groups artifacts were placed above each other, and similarities among the groups were identified (see Figure 3c). The workshop helped to clarify the system requirements and how they can be integrated into the nurses' daily workflow.

\section{Further Design Process}

Guided by the insights from our workshops, we applied further UX design methods to develop the design and interaction concept of NurseCare. We identified essential use cases that helped us to focus on key tasks and made use of personas, user scenarios, and the iterative sketching of design ideas.

To identify usability flaws early in the design process, we implemented a click-through prototype and evaluated it in a Cognitive Walkthrough. The evaluation was conducted with two computer-science students (both female), who had participated in workshop II. They were 23 and 29 years of age. The analytical inspection helped to identify structural inconsistencies and improve the design.

\section{NurseCare: The Final Implementation}

The final implementation of NurseCare consists of two components, a wearable, and an Android smartphone app.

The wearable mainly consists of a MetaMotionR sensor (version 'R1') [17] and a chest-belt. We created a 3d-printed case for the sensor, which leaves the micro-USB port accessible for charging (see Figure 4a). The chest-belt provides a pocket that can hold the sensor. The pocket was custom created and sewed to the chest-belt. A velcro strap allows a simple removal and insertion of the sensor (see Figure 4b). The chest-belt has a clasp on the opposing side to the pocket that holds the sensor. Thus, a user can easily put the sensor on in the morning, wear it at the center of the back to detect risky movements during work, and put it off in the evening (see Figure 4c).

The smartphone app can be connected to the sensor on the apps start screen via Bluetooth (accessible by touching the house icon visible in the left, bottom corner of the interface in Figure 4d). Based on the main requirements derived from workshop I $\left(\mathrm{R}_{1}-\mathrm{R}_{5}\right)$, the app provides five main features:

Real-time feedback $\left(R_{l}\right)$ is provided based on the accelerometer data of the sensor. The data are streamed from the sensor to the smartphone in real time. The angle between an upright stance and the user's current posture is computed. Thresholding is applied to determine if a user receives feedback. Muckell et al. [23] determined a gold standard for different risk metrics and patient transfers. The gold standard is based on the performance of a professional physiotherapist with over 15 years of experience. For upright stance, the gold standard suggests threshold angles for the two different patient-transfers bed-to-chair $\left(55.79^{\circ}\right)$ and chair-to-chair $\left(45.19^{\circ}\right)$. As the type of patient transfers that nurses need to conduct throughout a day is dependent on many aspects, like the condition of the patients that they transfer, we could not be sure which transfers our end users will conduct the most as part of their daily work. Thus, we decided to use a threshold value of $50^{\circ}$, which approximately corresponds to the mean of both gold-standard measurements. If a user exceeds the threshold, vibrotactile feedback is provided by a vibration of the smartphone.
Long-term feedback $\left(R_{2}\right)$ is accessible in the form of a 'movement profile' (see Figure 4d). The workshop participants saw it as important to know at what time of the day the system detected risky movements. The idea was that such a feature could help to reflect over a workday, as it allows users to relate back to events that happened at a certain time. For example, if the app shows a large number of risky movements between 9:15 and 9:30, a nurse might remember a specific situation that caused the risky movements. The 'movement profile' provides nurses with a day-based overview. A bar is shown for each day since a user began to use the system. A bar reflects how much time the user spent in a bent posture for the respective day. The overview can be scrolled to the left and right to move backward and forward in time. Inspired by the InformationSeeking Mantra [31], a user can select a bar in the overview to access a more detailed hour-based view which is shown below the overview. In addition, the selected bar is highlighted, and the user is provided with a brief summative feedback which is shown above the bar. Depending on the minutes a user spent in a bent posture for the respective day, the summative feedback either contains praise or motivates the user to do better in the future. The hour-based view works similar to the overview. A user can also select an hour to open a third minute-based view that reflects the selected hour in detail. Figure $4 d$ shows the expanded form of the 'movement profile.'

Mobile instructions $\left(R_{3}\right)$ are provided in the 'coach' section (see Figure 4e). The app provides eight animated videos for different Kinaesthetics-based patient transfers. The instruction videos were created from $3 \mathrm{~d}$ motion capture data that were produced as part of a research project. For the capture, a professional Kinaesthetics teacher with 16 years of experience with Kinaesthetics demonstrated the transfers together with a student who acted in the role of the patient. The videos were split into different steps that are important for the respective patient transfer. The steps are indicated by numbers in the timeline below the video. In the lower half of the interface, the 'coach' section provides a scrollable list with information related to each of the transfer's steps. For each step, the respective list item can be unfolded to reveal a more detailed description. If a specific part of the Kinaesthetics Care Conception is related to the step, it is also listed as part of the detailed description and a light bulb icon is shown to the right of it. Upon tapping on the light bulb, a popup window shows a description of the related part of the Kinaesthetics Care Conception. The videos change the perspective dependent on the information that is most relevant to the respective step. The changes in perspective were defined by the Kinaesthetics teacher who aided the motion capture. The teacher also corrected the texts that are used in the app. Furthermore, as part of the workshops, participants wished for a possibility to store instructions and notes related to patients. This could, for example, allow a quick rewatching of a transfer that worked well for the respective patient. NurseCare provides a 'patients' section, which can be accessed via a tap on the second button from the right in the bottom navigation bar of the interface (see Figure 4e). It offers the possibility to add profiles for patients, including their name, room number, their movement capability, and links to instructions for transfers that work especially well for the respective patient. 

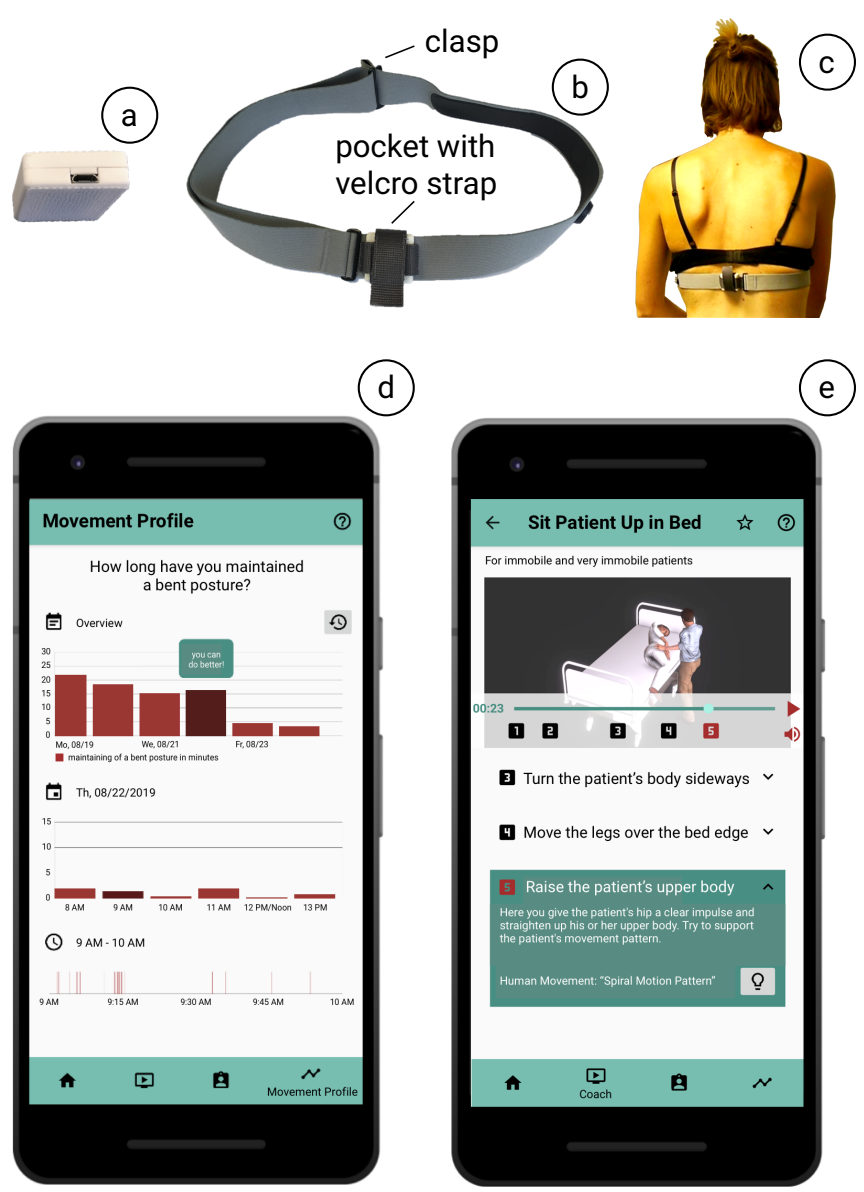

Figure 4. NurseCare: The final implementation. (a) sensor with 3dprinted case, (b) chest-belt with sensor, (c) chest-belt worn by a user, (d) long-term feedback, (e) mobile instructions. The smartphone app's user interface is translated from German (original language) to English. (Material design icons in (d) and (e), OGoogle LLC; Humans in (e), OReallusion Inc.; Hospital furniture in (e), OTurboSquid Inc.)

Rewards $\left(R_{4}\right)$ aim to motivate the user to move more ergonomically. They were implemented as 'badges' like sketched out by participants of workshop I. The 'home' screen shows three grayed out badges. The badges are phased. For the first, a user needs to achieve one hour with less than 60 risky movements of the back, for the second two, and for the third three hours.

The reminder $\left(R_{5}\right)$ was desired by participants to additionally remind them to work in a more ergonomic way. It was implemented in the form of a push notification. The time for the notification can be set by each user individually in the settings of the app. It can also be turned on and off.

\section{EVALUATION: 'IN-THE-WILD’ USER STUDY}

To our knowledge, previous research does not provide empirical evidence regarding the use of a system that promotes the ergonomic transfer of patients based on Kinaesthetics in a clinical setting during work. To evaluate how well a system like NurseCare can address nurses' needs, we conducted a qualitative mixed-methods user study 'in-the-wild.' Compared to a lab setting, an 'in-the-wild' study can provide a higher ecological validity, and reveal aspects related to the usage context [26] (e.g., [25]). In our evaluation, nine nursing-care students used NurseCare for multiple days at home and work. We addressed the three research questions $R_{1}-R_{3}$ :

$R Q_{1}$ : Does a system like Nurse Care provide a high user experience, adequate for use in the nurses' complex work domain?

$R Q_{2}$ : To what extent can a system like NurseCare help to promote ergonomic work and the application of Kinaesthetics?

$R Q_{3}$ : Do nurses prefer a system like NurseCare compared to existing support and learning materials?

\section{Participants}

Nine nursing-care students (five female) were recruited with the help of a nursing-care school. The participants and the school which aided the recruitment were different from the ones who supported the design of NurseCare in the form of the two workshops. The nursing-care education in Germany alternates between school blocks and clinical work blocks, which each usually span multiple consecutive weeks. All of the participants had work experience from work in a clinical context previous to the 'in-the-wild' user study. During the conduct of the study, all participants worked in different departments of the same clinic, which is associated with the mentioned nursing-care school. The participants were between 18 and 31 years of age $(M=23, S D=4.33)$. Six participants were in the second year of their education. The other three were in the third year. All of them had participated in a Kinaesthetics Basic Course during the first year of their education.

\section{Regulations}

The head of the nursing-care school, the clinic's workers council, and the clinic's privacy officer approved the study. At the time of the study, the clinic did not allow the use of smartphones by nurses during work. This is likely to change in the future, as other clinics in Germany and in other countries already employ mobile devices to access electronic medical records (e.g., [28]). For the study, the clinic's workers council issued a special permit that allowed the use of NurseCare by participants in the clinic. To ensure compliance with the clinic's hygiene regulations, participants had to use a liquid-repellent cover for the smartphone during work. The cover allowed the normal use of all common touch interactions (e.g., selection of buttons with a finger tap or the scrolling of lists). Furthermore, as part of the feature 'mobile instructions', we implemented the possibility to store instructions and related information, specific to a patient. However, to rule out any violation of patients' privacy, we did not seriously evaluate the patient-specific instructions as part of the 'in-the-wild' study. The patient-specific instructions were available in the app, but the participants' were instructed that they are not permitted to enter any information related to the clinic's patients. Previous to the use of NurseCare, all participants consented in written form, that they will not record any data related to patients while they use the smartphone in the clinic.

\section{Measurements}

Before and after the 'in-the-wild' use of NurseCare, a 'Self Evaluation Questionnaire' with custom 5-point Likert Scale questions was used to capture potential changes in participants' 
understanding of Kinaesthetics, and the presence of Kinaesthetics and ergonomic work as part of their work life. The questionnaire was extended with the questions number 22-28 of the Kinaesthetics Competence Self-Evaluation scale [12, 13], which measure how well a person can apply different aspects of Kinaesthetics. During the 'in-the-wild' use, participants were asked to fill a diary on a daily basis. The diary was integrated into the smartphone app. The participants were reminded by a daily push-notification to fill the diary. The notification appeared each day at the same time, at the end of the late shift. The diary was used to capture how stressful participants experienced their day, how practical they found the use of NurseCare in the clinic, and to what extent NurseCare helped them to apply Kinaesthetics and to pay more attention to work in an ergonomic manner. Participants' usage times of the system were captured by logging. Succeeding the 'in-the-wild' use, a custom 'System Evaluation Questionnaire' with 5-point Likert Scale questions was used to capture participants' experience with NurseCare. Related to $\mathrm{RQ}_{2}$, the questionnaire includes questions about how well NurseCare aided ergonomic work and the application of the Kinaesthetics Care Conception. It was complemented with the System Usability Scale [5], and a semi-structured interview. The semistructured interview was conducted to gain a deeper insight in the usability of NurseCare, users' experience with the system and its different features, how the system helped to apply Kinaesthetics and work in an ergonomic manner, and participants' preferences of NurseCare in contrast to existing support and learning materials. Audio recordings were created for all interviews. To extract information from the interviews, we conducted a thematic analysis. The analysis was based on the procedure described by Virginia and Clarke [4]: First, we transcribed all audio recordings. This step helped to familiarize us with the data and revealed initial ideas about potentially interesting aspects. Second, we assigned preliminary codes to parts of the data that seemed interesting. Third, we compared all codes to generate themes that may combine multiple codes. Fourth, we reviewed the themes in an iterative process. Themes that did not contain enough codes were omitted, while others were split in multiple themes or combined with other themes. Fifth and sixth, the themes were named, and finally documented, including a quantification of the results (i.e., we counted similar statements of participants).

\section{Procedure}

As a consequence of the 'in-the-wild' setting, it was not possible to ensure that all participants began and ended their participation in the study at the same time and that they used the system for an exact equal span of time. The participants had different work shifts which started and ended at different times, and personal appointments in their free time. Both complicated the scheduling for the study. For each participant, the study spanned over five days, and the 'in-the-wild' use was framed by two sessions: an introductory session (day one), and a closing session (day five).

\section{Introductory session (day one):}

In a 45 minutes introductory session in a lab room, the participants were asked to sign an informed consent and fill out a demographic questionnaire. Subsequent, they filled the 'Self
Evaluation Questionnaire.' Afterward, the smartphone app was installed on the participants' personal smartphone if the smartphone was compatible and if the participant agreed. This was the case for six participants. The other three participants received a loan unit in the form of a Google Pixel 3. Participants also received the chest-belt with the sensor and the liquid-repellent cover for the smartphone and were briefly introduced to NurseCare. As part of this, the diary was described to them, and they were asked to fill it during the 'in-the-wild' use.

\section{'In-the-wild' use:}

Following the initial session on day one, the participants used NurseCare until day five during work and at home. It was assured that each participant used NurseCare at least during three consecutive workdays.

\section{Closing session (day five):}

Succeeding the 'in-the-wild' use, on day five the participants returned all lone materials as part of a one-hour closing session in a lab room. They also filled the System Usability Scale, completed the 'Self Evaluation Questionnaire' a second time, and filled the 'System Evaluation Questionnaire' in the given order. Following this, we conducted the semi-structured interview. The participants received 30 Euro as compensation.

\section{Findings \& Discussion}

In this section, we report our findings and discuss them in relation to our three research questions. Our evaluation investigated users' experience with NurseCare $\left(\mathrm{RQ}_{1}\right)$, to which extent the system can help to promote ergonomic work and the application of Kinaesthetics $\left(\mathrm{RQ}_{2}\right)$, and users' preferences between NurseCare and existing support and learning materials $\left(\mathrm{RQ}_{3}\right)$. The evaluation was conducted in German. All of the reported results, including quotes, were translated from German to English. Statements made by different participants are distinguished based on participant ids, which consist of the letter $P$, followed by a number for the respective participant.

\section{$R Q_{1}:$ User Experience}

Six of the nine participants reported problems related to the Bluetooth connection between the smartphone and the wearable. Due to these problems, four of the participants were only able to connect the smartphone with the wearable during two work shifts $\left(\mathrm{P}_{2}, \mathrm{P}_{3}, \mathrm{P}_{5}, \mathrm{P}_{7}\right)$. Excluding the shifts for which the wearable could not be connected, the log files show that participants connected the smartphone and wearable for 05:38:44 hours on average per day ( $\mathrm{SD}=02: 02: 54$ hours). Despite the connection issues, all participants considered NurseCare as easy to use. For example, one participant stated:

\section{"[NurseCare] is really easy to integrate into everyday life.” $\left(\mathrm{P}_{6}\right)$}

This is confirmed by the results of the System Usability Scale. With a mean score of 88.6, the usability of NurseCare was rated as excellent [2]. Also confirming this finding, the mean scores of the 'System Evaluation Questionnaire' indicate that participants would, on average, agree to recommend NurseCare to a colleague and consider the integration of NurseCare in current practices as much desirable (see Figure 5). 


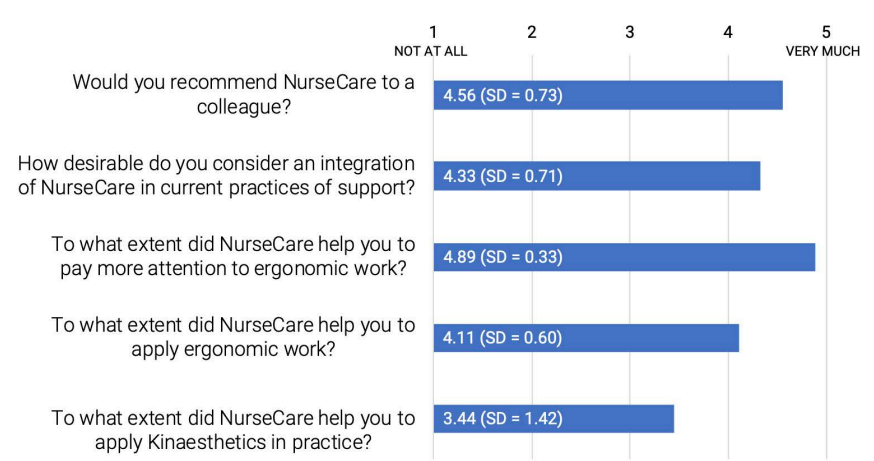

Figure 5. Mean scores of the Likert Scale questions in the custom 'System Evaluation Questionnaire' $(1=$ not at all, $5=$ very much $)$.

\begin{tabular}{|c|c|c|}
\hline $\begin{array}{l}\text { Real-time } \\
\left.\text { feedback ( } R_{1}\right)\end{array}$ & $\begin{array}{l}\text { + makes aware of risky situations }(\mathrm{N}=9) \\
+ \text { persistent feedback }(\mathrm{N}=8)\end{array}$ & $\begin{array}{l}\text { - annoying when bending of the back } \\
\text { cannot be avoided }(\mathrm{N}=4) \\
\text { - occasionally irritating because of } \\
\text { inaccuracy }(\mathrm{N}=2)\end{array}$ \\
\hline $\begin{array}{l}\text { Long-term feed- } \\
\text { back }\left(\mathrm{R}_{2}\right)\end{array}$ & $\begin{array}{l}\text { + interesting/exciting statistics }(N=5) \\
\text { + helpful }(N=4) \\
\text { + easily undestandable }(N=4) \\
\text { + supports reflection related to specific } \\
\text { situations/times at which problems } \\
\text { were detected are helpful }(N=4)\end{array}$ & $\begin{array}{l}\text { - showing the times at which problems } \\
\text { were detected without further information } \\
\text { is insufficient to link back to specific } \\
\text { situations }(\mathrm{N}=2)\end{array}$ \\
\hline $\begin{array}{l}\text { Mobile } \\
\text { instructions ( }\left(R_{3}\right)\end{array}$ & $\begin{array}{l}\text { + beneficial to understand the } \\
\text { Kinaesthetics Care Conception }(\mathrm{N}=8) \\
+ \text { good refresher }(\mathrm{N}=3)\end{array}$ & $\begin{array}{l}\text { - limited amount of videos }(N=1) \\
\text { - videos not with real actors }(N=1)\end{array}$ \\
\hline Rewards ( $\left.R_{4}\right)$ & + perceived as good motivation $(\mathrm{N}=5)$ & - not perceived as motivational $(\mathrm{N}=4)$ \\
\hline Reminder (R5) & + increases the awareness $(\mathrm{N}=4)$ & - superflous $(N=5)$ \\
\hline
\end{tabular}

Figure 6. Positive (+) and negative (-) aspects of NurseCare's features. Each feature is based on a requirement from workshop I $\left(R_{1}-R_{5}\right)$. The number of participants who stated an aspect is denoted with $N$.

When asked about the positive and negative aspects of the different features of NurseCare, participants named much more positive aspects, compared to negative ones (see Figure 6). Especially the three key features real-time feedback, long-term feedback, and mobile instructions were largely appreciated. For example, one participant remarked:

\section{"Actually, after the first day, I realized that whenever the sensor reminded me 'do not do that,' actually the next day, some movements were, funnily enough, improved automatically. So, for instance, that I bend my knees instead of leaning forward." $\left(\mathrm{P}_{5}\right)$}

However, the participants also mentioned some potential for improvement. They especially noted limitations related to the in-situ feedback. Participants reported that the vibrotactile feedback can be annoying in situations in which it is unavoidable to bend down $\left(\mathrm{P}_{1}, \mathrm{P}_{4}, \mathrm{P}_{5}, \mathrm{P}_{9}\right)$, and suggested to extend the sensory features of NurseCare, to improve accuracy and make the feedback more detailed by measuring forces on other body parts like the arms $\left(\mathrm{P}_{4}-\mathrm{P}_{6}\right)$, legs $\left(\mathrm{P}_{5}\right)$, and neck $\left(\mathrm{P}_{4}\right)$.

Finding 1.1: The subjective usability of NurseCare is high, and the participants experienced the features of NurseCare as mostly positive. However, there is potential to improve NurseCare further. Especially limitations related to the in-situ feedback should be addressed in the future.

All participants felt that NurseCare was easy to embed in their work context. They saw the smartphone as well suited to

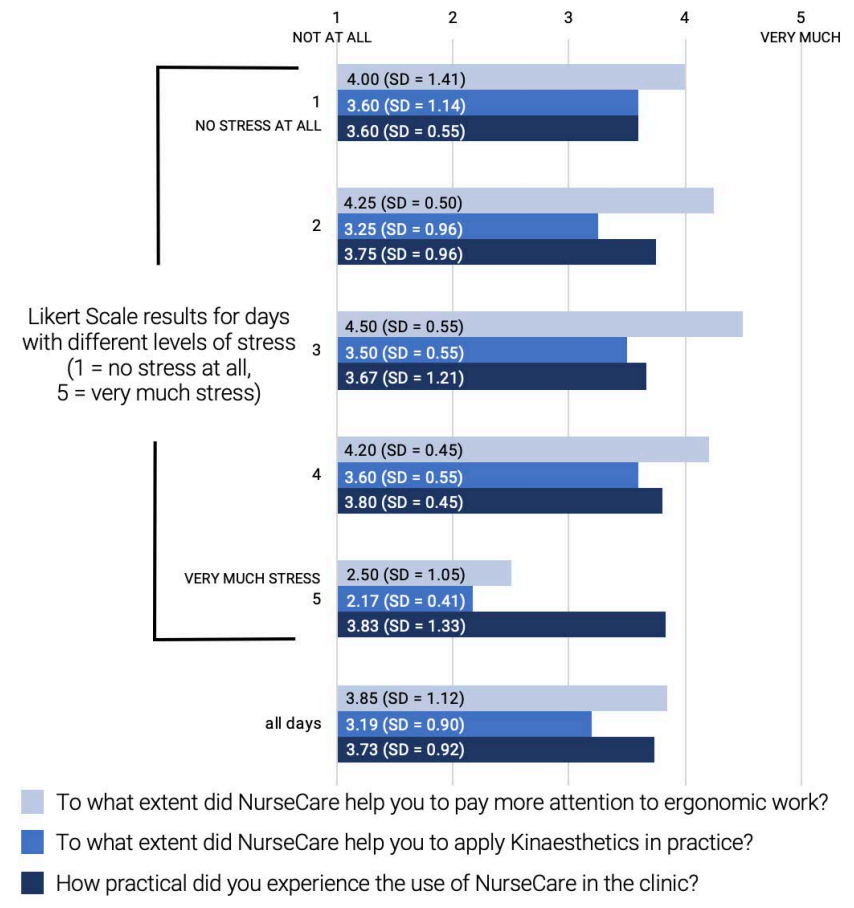

Figure 7. Mean Scores of the diary's Likert Scale questions related to ergonomic work, Kinaesthetics, and practicability of NurseCare for days with different levels of stress and all days. For example, the topmost three bars represent the answers to the Likert Scale questions for all days in which the users had a stress level of 1 , which corresponds to 'no stress at all.' Participants' responses for days in which they could not connect the wearable with the smartphone app are excluded for all bars.

access the different features of NurseCare. For example, four participants explicitly mentioned the smartphone as practical to view instructions $\left(\mathrm{P}_{2}, \mathrm{P}_{6}, \mathrm{P}_{8}, \mathrm{P}_{9}\right)$. They liked it that it is mobile and always available. Regarding the wearable as part of NurseCare, six of the nine participants stated that the chest belt is comfortable during work $\left(\mathrm{P}_{1}, \mathrm{P}_{2}, \mathrm{P}_{6}-\mathrm{P}_{9}\right)$. One stated:

"The chest belt was comfortable to wear. It did not bother me at all. Sometimes I even forgot it unless it started vibrating." $\left(\mathrm{P}_{9}\right)$

Although none of the participants had major problems with the wearable during work, two noted that it could slip in warm conditions $\left(\mathrm{P}_{3}, \mathrm{P}_{6}\right)$, and two stated that the wearable is inconvenient when leaning against the backrest of a chair $\left(\mathrm{P}_{4}, \mathrm{P}_{5}\right)$. To simplify the systems use further, six participants suggested embedding the wearable's technology in a smart garment or similar in the future $\left(\mathrm{P}_{2}-\mathrm{P}_{5}, \mathrm{P}_{7}, \mathrm{P}_{8}\right)$.

The stress that nurses experience during work can change from day to day, and also between working at different wards. Based on the diary results, participants average rating of how stressful they perceived their day between 1 (not at all), and 5 (very much) is 3.13 for all days in which they used NurseCare $(\mathrm{SD}=1.48)$. Our results indicate that the participants found NurseCare practical, independent of how much stress they experienced during work (see Figure 7). 
Finding 1.2: The participants perceived NurseCare as adequate to support them in their complex work domain. The combination of the smartphone and the wearable were practical to use, independent of how much stress the participants experienced during a day. However, for permanent use in a clinical environment, the Bluetooth connection between the wearable and the smartphone should be improved, and the comfort of the wearable should be increased. The integration of the wearable's technology as part of a smart garment could be a feasible approach.

\section{$R Q_{2}$ : Ergonomic Work and Application of Kinaesthetics}

During the semi-structured interviews, the participants confirmed that NurseCare addresses an important topic. For example, one participant stated:

"I think it is a very important topic, especially to relieve the burden on nursing-care because a lot of colleagues suffer from back pain and stop working because of that. Therefore I really like [NurseCare]. It is a good approach.” $\left(\mathrm{P}_{3}\right)$

When considering how well Nurse Care can promote the application of the Kinaesthetics Care Conception to facilitate ergonomic work, participants' responses in the diary (see Figure 7) and in the 'System Evaluation Questionnaire' (see Figure 5) point into the same direction. Participants' ratings indicate that Nurse Care could help them to apply the Kinaesthetics Care Conception and work more ergonomic.

"Now, I focus more on my back or rather my position during work." $\left(\mathrm{P}_{3}\right)$

The interview results suggest that especially the in-situ, and the longterm feedback were seen as beneficial by the participants to promote ergonomic patient transfers. For example, they stated:

\section{"Often, the feedback was correct. Often it vibrated when I was at the same time realizing: 'Now I am moving in an unhealthy way!'.” $\left(\mathrm{P}_{4}\right)$ \\ "Yes, you look at [the movement profile] because it is interesting, and you ask yourself: 'Okay, what was the problem at 12 o'clock?'." $\left(P_{8}\right)$}

Specifically related to Kinaesthetics, the 'Self Evaluation Questionnaire' which was filled before and after the usage of NurseCare revealed a statistically significant difference for the Likert Scale question "As how applicable do you consider Kinaesthetics?". A t-test $(\mathrm{t}(8)=-2.4, p=0.043)$ showed a significant difference in the mean scores before $(\mathrm{M}=3.33$, $\mathrm{SD}=0.71)$ and after $(\mathrm{M}=4.11, \mathrm{SD}=0.78)$ the usage of NurseCare. The results indicate that the participants considered Kinaesthetics more applicable after working with NurseCare than before. Although the differences between the mean values of the other questions in the 'Self Evaluation Questionnaire' also suggest a tendency towards an increase of participants' knowledge related to the application of Kinaesthetics, t-tests revealed no statistically significant differences for any of the questions (all $p>0.05$ ). Based on participants' statements, especially NurseCare's mobile instructions were seen as beneficial to aid the understanding of Kinaesthetics. Eight of the nine participants perceived the feature as helpful $\left(\mathrm{P}_{1}-\mathrm{P}_{3}, \mathrm{P}_{5}-\mathrm{P}_{9}\right)$. The mobile instructions helped to conduct more ergonomic patient transfers, but also to reflect upon past experiences:

"[NurseCare] actively helped me - especially moving the patient up - to once really work it out in a different manner than just pulling the patient up." $\left(\mathrm{P}_{3}\right)$

"I watched the videos at home. I thought about a situation in the past, where I had problems, and then rewatched a video for that." $\left(\mathrm{P}_{6}\right)$

When looking at participants' questionnaire responses, for both, the diary (see Figure 7) and the 'System Evaluation Questionnaire' (see Figure 5), the responses indicate, that the support of Nurse Care regarding ergonomic work is higher than regarding the application of the Kinaesthetics Care Conception. Participants confirmed this during the interview. For example, when asked if s/he felt supported in applying Kinaesthetics, $\mathrm{P}_{9}$ pointed out:

"I would say yes and no. I rather focused on ergonomic work, so not how to perform it in a Kinaesthetics manner with the patient, but rather like: 'Oh gosh now I am bending forward to the patient, it is better to stay straight in the back.' So rather these ergonomic work routines, but that is not wrong. (laughs)" $\left(\mathrm{P}_{9}\right)$

Participants stated that they often rather applied simple ergonomic rules that are conveyed by NurseCare, like lifting the bed to a proper elevation for work, instead of complete Kinaesthetics-based patient transfers. $\mathrm{P}_{7}$ argued that more practice is required to realize patient transfers based on $\mathrm{Ki}$ naesthetics. The results of the 'Self Evaluation Questionnaire,' which was filled before the use of NurseCare, show that participants did not feel very confident in dealing with Kinaesthetics. The 5-point Likert Scale question "How confident do you feel about dealing with Kinaesthetics?" was rated with a mean score of $2.56(\mathrm{SD}=0.73,1=$ not at all, $5=$ very much $)$. Related to this, $\mathrm{P}_{1}$ highlighted the fact that Kinaesthetics is often not actively applied and supervised in the clinic at present:

"[...] but finally the lack of knowledge is quite a problem, and also the clinical facilitators do not keep an eye on Kinaesthetics.” $\left(\mathrm{P}_{1}\right)$

One participant suggested that the future use of a system like Nurse Care should be supported by a person familiar with the system and that additional support to refresh the knowledge about Kinaesthetics would be helpful.

"It would be smart if there was someone who is well versed in the system and also uses it and if there was also a room where Kinaesthetics is also explained to beginners again.” $\left(\mathrm{P}_{6}\right)$

This can help to address the current lack of knowledge and increase the application of Kinaesthetics. In relation, $\mathrm{P}_{1}$ also expressed the wish for a place to repeat Kinaesthetics-based patient transfers after the Kinaesthetics Basic Course. 
Finally, the diary responses also indicate a lower support by NurseCare for days, which the participants perceived as very stressful (see Figure 7). For very stressful days, the participants reported a lower subjective support of NurseCare for ergonomic work and the application of Kinaesthetics into practice. Participants' interview statements indicate that on very stressful days, the high time pressure leaves few room for the application of Kinaesthetics and the use of a supportive system. For example, $\mathrm{P}_{4}$ explicitly stated that NurseCare helped "a lot to work in a back-friendly way", but also remarked:

"I did not apply Kinaesthetics [by using NurseCare], but that was rather due to time. [...] I could not have stopped for a moment and watched a video" $\left(\mathrm{P}_{4}\right)$

Finding 2: Except in very stressful situations, NurseCare provides a high subjective support to promote ergonomic work and a good but limited subjective support for the application of the Kinaesthetics Care Conception. The use of NurseCare for the duration of the study led participants to value the applicability of Kinaesthetics significantly higher, but could not significantly improve their expertise related to the application of the Kinaesthetics Care Conception. A longterm usage of a system like NurseCare might show a stronger increase in knowledge related to the application of Kinaesthetics. Independent of that, further support for the acquisition of knowledge related to Kinaesthetics-based patient transfers is required. A more holistic approach that combines NurseCare with an additional component that emphasizes on the training of Kinaesthetics-based patient transfers, for example, in the training room of a school or clinic, seems promising.

\section{$R Q_{3}:$ Preference of Support}

All of the participants reported that the current support and materials are very limited:

"Compared to current practices [of support]? To be honest... which practices? Unfortunately, a lot of colleagues in our hospital do not even know the concept of Kinaesthetics, because most of them are older [than the students], or-like us-they had [Kinaesthetics] in the very beginning [of their education] and afterward it has never been mentioned again. So I think [NurseCare] would win recognition and help to refresh [the knowledge about Kinaesthetics] also among those who had heard about Kinaesthetics some time ago." $\left(\mathrm{P}_{5}\right)$

All of the participants wished for a future integration of NurseCare to extend the support during their work practice. The participants also expressed that they would wish an early introduction of the system directly during or after the Kinaesthetics Basic Course $\left(\mathrm{P}_{2}, \mathrm{P}_{4}, \mathrm{P}_{6}-\mathrm{P}_{9}\right)$. This can help to prevent negative health implications early on during the education of nursing-care students. Furthermore, three participants explicitly wished for the integration of NurseCare in combination with electronic medical records in the future $\left(\mathrm{P}_{3}, \mathrm{P}_{5}, \mathrm{P}_{7}\right)$. To do so, could help to share ergonomic problems related to the transfer of a specific patient with colleagues, and could al- low the use of the generated data by decision-makers to keep an eye on the exposure of the nurses' health and to initialize changes which might improve the overall work conditions.

"I have those visions, that when you do the shift changes, then you see directly [in the electronic medical record]: My colleague, he only bends down in a risky manner caring for this patient, maybe this patient is tiring. And then I enter the room with specific awareness or just with the idea that I will solely work ergonomic or pay additional attention to that." $\left(\mathrm{P}_{3}\right)$

Finding 3: Our results confirm that there is nearly no support for the promotion of ergonomic patient transfers available at present. All participants wished for a future integration of NurseCare to improve the support during work. According to participants' suggestions, an early integration - preferably directly during or after the Kinaesthetics Basic Course-, and a combination of NurseCare with electronic medical records seems promising.

\section{Limitations}

We decided to evaluate NurseCare 'in-the-wild'. Compared to a lab study, the 'in-the-wild' setting allowed us to gain a far deeper insight into the extent to which the system can support nurses during work. Although to have real end-users who use the system in their real work context allowed us to gather information with a high ecological validity, the 'in-the-wild' setting also imposed several limitations.

During the evaluation, some of the participants experienced problems with the Bluetooth connection between the wearable and the smartphone. One likely reason for this issue is that the participants could use their own smartphone during the evaluation. Although the issue needs to be resolved to allow the future permanent use of NurseCare during work, it did not have a strong negative impact on the overall positive qualitative results of the evaluation, which were the focus of interest.

To limit the organizational overhead, we recruited only participants who went to the same nursing-care school and worked at the same clinic. Consequently, all participants were rather young (between 18 and 31 years of age) and inexperienced (six were in the second, three in the third year of their education). A future study with older and more experienced nursing-care workers is required to determine if our findings are also valid for this group of persons.

The study duration was limited to five days per participant. A future long-term study would be necessary to investigate how a system like NurseCare would be perceived when employed more permanently. Furthermore, our evaluation focused on subjective data. Future work might investigate more objective measures, for example, by involving Kinaesthetics teachers who rate the movements of participants before and after the long-term use of a system like NurseCare.

Furthermore, the participants worked at different wards and in different shifts while they took part in the evaluation. Although this could be seen as a limitation, as not all participants 
followed the exact same work routine during the study, we would argue that for our evaluation it is also a strength. The diversity increased the ecological validity of our findings and shows that the findings are not only valid for a specific task, but for a broad range of nurses' work-life experiences.

\section{IMPLICATIONS}

The implications of this work inform the design and integration of mobile systems that promote the ergonomic transfer of patients, as well as future research in this direction.

The results of the two workshops as part of our design process and the final evaluation of NurseCare emphasize the importance of providing support for the promotion of ergonomic patient transfers, based on the Kinaesthetics Care Conception. NurseCare is to our knowledge (i) the first mobile system that provides instructions and feedback to promote the application of Kinaesthetics-based ergonomic patient transfers during work, and (ii) the first such system that was evaluated in an 'in-the-wild' user study that was conducted in a clinical setting.

Our results indicate that our user-centered design process led to a system with a high user experience adequate to the nurses' complex work domain. Furthermore, the results provide insights related to the perception of NurseCare's features by the participants. These insights can inform the future design and research of similar systems. The results indicate that the participants especially appreciated the three features: (i) real-time feedback, (ii) long-term feedback, and (iii) mobile instructions. However, they also stated that the in-situ feedback could be annoying when they could not avoid it to bend their back. But how to identify if a nurse is in a situation in which bending of the back is unavoidable? Future research might investigate different approaches to address this issue while taking the special requirements of nurses' work domain into account. Furthermore, Nurse Care uses a rather simple threshold-based tracking, which is based solely on one sensor in a chest belt. Based on participants' suggestions, future research might improve the accuracy of our tracking approach and compare our single-sensor approach with other approaches, which include measurements for other parts of the body. Future work may also extend the feedback by incorporation of further risk metrics aside from measuring if a user is in an upright stance. Previous work already showed [23], that a larger number of wearable sensors (the authors used 17) can allow for the mobile detection of further risk metrics which are relevant to the ergonomic transfer of patients. However, this raises the question, how a larger number of sensors might be integrated into a future system that is practical and unobtrusive during work in a clinical setting. Based on participants' suggestions, integrating the sensors as part of a smart garment might be a feasible approach to allow for a high comfort during work.

Furthermore, with the exception of very stressful days, participants' subjective responses indicate that NurseCare provides a high support to promote ergonomic work and a good but limited support for the application of Kinaesthetics during work. Future work may investigate ways to increase the support during very stressful situations. Related to this, it is also interesting to investigate if a long-term use of a system like
Nurse Care affects nurses' behavior during very stressful situations. A long-term use might help to internalize simple ergonomic rules and extend nurses' knowledge about Kinaesthetics, which might also reflect positively on their behavior during stressful situations. Furthermore, our results imply that future work should strive to increase support for the acquisition of knowledge related to Kinaesthetics. Based on participants' suggestions, a more holistic approach, which includes support for the training and practice of Kinaesthetics-based patient transfers, seems promising.

Finally, our results show that all participants of the in-thewild' evaluation wished a future permanent integration of a system like NurseCare. Participants' statements imply that a future integration might be realized as follows: To help to prevent it that nurses adopt unhealthy ways to transfer patients, Nurse Care is introduced early during nurses' education, for example, in connection with the Kinaesthetics Basic Course. NurseCare supports nurses with an improved in-situ feedback and mobile instructions during work. As NurseCare is integrated into the electronic medical records, nurses can store and share information that is important for the transfer of specific patients. Furthermore, decision-makers use the sensor data of NurseCare in connection with the information of the medical records to improve the work conditions of nurses. For example, a nurse who shows a large number of risky movements over several days might get the offer to participate in a Kinaesthetics Refresher Course. When at home, or in a break, nurses can use Nurse Care to reflect on their movement data individually. Eventually, striving towards a more holistic approach, the mobile system could further be extended by an additional system or component that supports the training and practice of Kinaesthetics-based patient transfers, e.g., in a training room in a clinic or school.

\section{CONCLUSION}

We presented NurseCare, a mobile system that aims to promote the practical application of ergonomic patient transfers based on the Kinaesthetics Care Conception. NurseCare addresses the problems: (i) that the manual transfer of patients as part of nurses' daily duties can pose a major risk factor for injuries to the back, and (ii) that there exists hardly any support for the integration of the Kinaesthetics Care Conception-a concept from nursing care which can help to address the first issue-into nurses' daily work practice. NurseCare was developed in a user-centered design process together with nurses. We evaluated Nurse Care with nine nurses-who did not participate in the design process - in a clinical setting 'in-the-wild.' Our results indicate that NurseCare provides a high user experience adequate to the nurses' work domain, a high subjective support to promote ergonomic work, and a good but limited subjective support for the application of the Kinaesthetics Care Conception. They furthermore reveal how NurseCare can be incorporated into, and extend existing practices.

\section{ACKNOWLEDGMENTS}

We thank all institutions, nursing-care students, nursing-care teachers, and members of the University of Konstanz who aided our work. Furthermore, we thank the German Federal Ministry of Education and Research (Grant no.: 16SV7591). 


\section{REFERENCES}

[1] European Kinaesthetics Association. 2008. Was ist Kinaesthetics? [GERMAN]. (2008). https: //www.kinaesthetics.net/download/eka/infoblaetter/ deutsch/Infoblatt_1_Was_ist_Kinaesthetics.pdf (Accessed: 2019-09-19).

[2] Aaron Bangor, Philip Kortum, and James Miller. 2009. Determining What Individual SUS Scores Mean: Adding an Adjective Rating Scale. J. Usability Studies 4, 3 (may 2009), 114-123.

http://dl.acm.org/citation.cfm?id=2835587.2835589

[3] Matthew Bonham. 2019. Augmented Reality Simulation Toward Improving Therapeutic Healthcare

Communication Techniques. In Proceedings of the 24th International Conference on Intelligent User Interfaces: Companion (IUI '19). ACM, New York, NY, USA, 161-162. DOI :

http://dx.doi.org/10.1145/3308557.3308726

[4] Virginia Braun and Victoria Clarke. 2006. Using thematic analysis in psychology. Qualitative Research in Psychology 3, 2 (2006), 77-101. DOI: http://dx.doi.org/10.1191/1478088706qp063oa

[5] John Brooke. 1996. SUS-A quick and dirty usability scale. In Usability evaluation in industry, Bernard Weerdmeester Patrick W. Jordan, Bruce Thomas, Ian Lyall McClelland (Ed.). Taylor \& Francis, London, UK, Chapter 21, 189-194. DOI :

http://dx.doi.org/10.1201/9781498710411

[6] Pedro Carvalho, Sandro Queirós, António Moreira, José Henrique Brito, Fernando Veloso, Miguel Terroso, Nuno F. Rodrigues, and João L. Vilaça. 2017. Instrumented vest for postural reeducation. In 2017 IEEE 5th International Conference on Serious Games and Applications for Health (SeGAH). IEEE, Perth, WA, Australia, 1-8. DOI:

http://dx.doi.org/10.1109/SeGAH.2017.7939300

[7] Jiachun Du, Qi Wang, Liesbet de Baets, and Panos Markopoulos. 2017. Supporting Shoulder Pain Prevention and Treatment with Wearable Technology. In Proceedings of the 11th EAI International Conference on Pervasive Computing Technologies for Healthcare (PervasiveHealth '17). ACM, New York, NY, USA, 235-243. DOI :

http://dx.doi.org/10.1145/3154862.3154886

[8] Maximilian Dürr, Ulrike Pfeil, Jens Müller, Marcel Borowski, Carla Gröschel, and Harald Reiterer. 2019. Learning Patient Transfers with Technology: A Qualitative Investigation of the Design Space. In Proceedings of Mensch Und Computer 2019 (MuC'19). ACM, New York, NY, USA, 79-90. DOI : http://dx.doi.org/10.1145/3340764.3340784

[9] Inga-Lill Engkvist, Mats Hagberg, Arvid Lindén, and Birgitta Malker. 1992. Over-exertion back accidents among nurses' aides in Sweden. Safety Science 15, 2 (1992), 97-108. DOI :

http://dx.doi.org/10.1016/0925-7535(92)90010-W
[10] Inga-Lill Engkvist, Ewa Wigaeus Hjelm, Mats Hagberg, Ewa Menckel, and Lena Ekenvall. 2000. Risk Indicators for Reported Over-Exertion Back Injuries among Female Nursing Personnel. Epidemiology 11, 5 (2000), 519-522. https:

//journals.lww.com/epidem/Fulltext/2000/09000/Risk

[11] André Fringer, Martina Huth, and Virpi Hantikainen. 2014. Nurses' experiences with the implementation of the Kinaesthetics movement competence training into elderly nursing care: a qualitative focus group study. Scandinavian Journal of Caring Sciences 28, 4 (jan 2014), 757-766. DOI :

http://dx.doi.org/10.1111/scs.12108

[12] Heidrun Gattinger. 2017. Development and evaluation of two instruments to assess nursing staff's competence in mobility care based on kinaesthetics. Ph.D.

Dissertation. University of Turku.

https://www.utupub.fi/bitstream/handle/10024/144030/ AnnalesD1310Gattinger.pdf? sequence $=1$

[13] Heidrun Gattinger, Beate Senn, Virpi Hantikainen, Sascha Köpke, Stefan Ott, and Helena Leino-Kilpi. 2017. Mobility care in nursing homes: development and psychometric evaluation of the kinaesthetics competence self-evaluation (KCSE) scale. BMC Nursing 16, 1 (2017), 67. DOI : http://dx.doi.org/10.1186/s12912-017-0257-8

[14] Agnes Grünerbl, Gerald Pirkl, Mark Weal, Mary Gobbi, and Paul Lukowicz. 2015. Monitoring and Enhancing Nurse Emergency Training with Wearable Devices. In Adjunct Proceedings of the 2015 ACM International Joint Conference on Pervasive and Ubiquitous Computing and Proceedings of the 2015 ACM International Symposium on Wearable Computers (UbiComp/ISWC'15 Adjunct). ACM, New York, NY, USA, 1261-1267. DOI:

http://dx.doi.org/10.1145/2800835.2807941

[15] Frank Hatch and Lenny Maietta. 2003. Kinästhetik: Gesundheitsentwicklung und menschliche Aktivitäten [GERMAN] (2 ed.). Elsevier, Urban \& Fischer Verlag, München.

[16] Zhifeng Huang, Ayanori Nagata, Masako Kanai-Pak, Jukai Maeda, Yasuko Kitajima, Mitsuhiro Nakamura, Kyoko Aida, Noriaki Kuwahara, Taiki Ogata, and Jun Ota. 2014. Self-Help Training System for Nursing Students to Learn Patient Transfer Skills. IEEE Transactions on Learning Technologies 7, 4 (2014), 319-332. DOI : http://dx.doi.org/10.1109/TLT.2014.2331252

[17] MBientLab Inc. 2019. mbientlab - MetaMotionR (MMR). (2019). https://mbientlab.com/metamotionr/ (Accessed: 2019-09-19).

[18] Finn Kensing and Jeanette Blomberg. 1998. Participatory Design: Issues and Concerns. Computer Supported Cooperative Work (CSCW) 7, 3 (sep 1998), 167-185. DOI :

http://dx.doi.org/10.1023/A: 1008689307411 
[19] Finn Kensing and Kim Halskov Madsen. 1991. Generating Visions: Future Workshops and Metaphors. In Design at Work, Joan Greenbaum and Morten Kyng (Eds.). Lawrence Earlbaum, Hillsdale, 155-168.

[20] Maietta-Hatch Kinaesthetics. 2019. Kinaesthetics Apps 'Kinaesthetics Care' and 'MH Kinaesthetics' [GERMAN]. (2019). https://www.kinaesthetics.com/at/apps.html (Accessed: 2019-09-20).

[21] Jan Kopetz, Daniel Wessel, Katrin Balzer, and Nicole Jochems. 2018. Smart Glasses as Supportive Tool in Nursing Skills Training. In Zukunft der Pflege : Tagungsband der 1. Clusterkonferenz 2018, Susanne Boll (Ed.). BIS-Verlag der Carl von Ossietzky Universität Oldenburg, Oldenburg, 137-141. https://srvg03.offis.uni-oldenburg.de/piz/wp-content/ uploads/2018/06/Zukunft-der-Pflege-Tagungsband-derClusterkonferenz-2018.pdf

[22] Tore J. Larsson and Ulf Björnstig. 1995. Persistent Medical Problems and Permanent Impairment Five Years after Occupational Injury. Scandinavian Journal of Social Medicine 23, 2 (1995), 121-128. DOI : http://dx.doi.org/10.1177/140349489502300207

[23] Jonathan Muckell, Yuchi Young, and Mitch Leventhal. 2017. A Wearable Motion Tracking System to Reduce Direct Care Worker Injuries: An Exploratory Study. In Proceedings of the 2017 International Conference on Digital Health (DH'17). ACM, New York, NY, USA, 202-206. DOI :

http://dx.doi.org/10.1145/3079452.3079493

[24] Vern Putz-Anderson, Bruce P. Bernard, Susan E. Burt, Libby L. Cole, Fairfield-Estill Cheryl, Lawrence J. Fine, Katharyn A. Grant, Christopher Gjessing, Lynn Jenkins, Joseph J. Hurrell, Nancy Nelson, Donna Pfirman, Robert Roberts, Diana Stetson, Marie Haring-Sweeney, and Shiro Tanaka. 1997. Musculoskeletal disorders and workplace factors: a critical review of epidemiologic evidence for work-related musculoskeletal disorders of the neck, upper extremity, and low back. Number 97-141. National Institute for Occupational Safety and Health, U. S. Department of Health and Human Services, Cincinnati, $\mathrm{OH}$.

https://www.cdc.gov/niosh/docs/97-141/default.html

[25] Yvonne Rogers, Kay Connelly, Lenore Tedesco, William Hazlewood, Andrew Kurtz, Robert E. Hall, Josh Hursey, and Tammy Toscos. 2007. Why It's Worth the Hassle: The Value of In-Situ Studies When Designing Ubicomp. In UbiComp 2007: Ubiquitous Computing, John Krumm, Gregory D Abowd, Aruna Seneviratne, and Thomas Strang (Eds.). Springer Berlin Heidelberg, Berlin, Heidelberg, 336-353. DOI :

http://dx.doi.org/10.1007/978-3-540-74853-3_20

[26] Yvonne Rogers and Paul Marshall. 2017. Research in the Wild. Synthesis Lectures on Human-Centered Informatics 10, 3 (2017), i-97. DOI : http://dx.doi.org/10.2200/S00764ED1V01Y201703HCI037
[27] Elizabeth B.-N. Sanders, Eva Brandt, and Thomas Binder. 2010. A Framework for Organizing the Tools and Techniques of Participatory Design. In Proceedings of the 11th Biennial Participatory Design Conference (PDC '10). ACM, New York, NY, USA, 195-198. DOI : http://dx.doi.org/10.1145/1900441.1900476

[28] Jan-Stephan Schweda. 2019. Wenn der Arzt mit dem Tablet kommt: Mehr Patientensicherheit durch digitale Daten im Krankenhaus [GERMAN]. (2019).

https://www.elisabeth-vinzenz.de/pressemeldungen/wennder-arzt-mit-dem-tablet-kommt-mehr-

patientensicherheit-durch-digitale-daten-im (Accessed: 2019-09-18).

[29] Maheswaran Shanmugam, Sunilvignesh Nehru, and Sathesh Shanmugam. 2018. A wearable embedded device for chronic low back patients to track lumbar spine position. Biomedical Research (0970-938X) Special Issue (2018), S118 - S123. D0I : http: //dx.doi.org/10.4066/biomedicalresearch.29-17-1304

[30] Naohiro Shibuya, B. T. Nukala, Amanda I. Rodriguez, J. Tsay, Tam Q. Nguyen, Steven Zupancic, and D. Y. C. Lie. 2015. A real-time fall detection system using a wearable gait analysis sensor and a Support Vector Machine (SVM) classifier. In 2015 Eighth International Conference on Mobile Computing and Ubiquitous Networking (ICMU). IEEE, Hakodate, Japan, 66-67. DOI : http://dx.doi.org/10.1109/ICMU.2015.7061032

[31] Ben Shneiderman. 1996. The eyes have it: a task by data type taxonomy for information visualizations. In Proceedings 1996 IEEE Symposium on Visual Languages. IEEE Comput. Soc. Press, Boulder, CO, USA, 336-343. DOI : http://dx.doi.org/10.1109/VL.1996.545307

[32] Julia Smedley, Peter Egger, Cyrus Cooper, and David Coggon. 1995. Manual handling activities and risk of low back pain in nurses. Occupational and Environmental Medicine 52, 3 (1995), 160-163. DOI : http://dx.doi.org/10.1136/oem.52.3.160

[33] Iwan Aang Soenandi, Meriastuti Ginting, and Budi Harsono. 2019. Real Time Floor Sitting Posture Monitoring Using K-Means Clustering. In Proceedings of the 2Nd International Conference on Software Engineering and Information Management (ICSIM 2019). ACM, New York, NY, USA, 194-198. D0I : http://dx.doi.org/10.1145/3305160.3305209

[34] Alison M. Trinkoff, Jane A. Lipscomb, Jeanne Geiger-Brown, and Barbara Brady. 2002. Musculoskeletal problems of the neck, shoulder, and back and functional consequences in nurses. American Journal of Industrial Medicine 41, 3 (2002), 170-178. DOI : http://dx.doi.org/10.1002/ajim. 10048

[35] Upright. 2019. Upright - Upright Go. (2019). https://www.uprightpose.com/products/ (Accessed: 2019-09-19). 
[36] Qi Wang, Marina Toeters, Wei Chen, Annick Timmermans, and Panos Markopoulos. 2016. Zishi: A Smart Garment for Posture Monitoring. In Proceedings of the 2016 CHI Conference Extended Abstracts on Human Factors in Computing Systems (CHI EA '16). ACM, New York, NY, USA, 3792-3795. DOI :

http://dx.doi.org/10.1145/2851581.2890262
[37] Xuzhong Yan, Heng Li, Angus R. Li, and Hong Zhang. 2017. Wearable IMU-based real-time motion warning system for construction workers' musculoskeletal disorders prevention. Automation in Construction 74 (feb 2017), 2-11. DOI :

http://dx.doi.org/10.1016/j.autcon.2016.11.007 